\title{
Evaluation of Seed Quality Parameters in Coriander (Coriandrum sativum $\mathbf{L}$ )
}

\author{
Raj Kumar Suman*, Kamal Kant, Surya Prakash Meena and Vijay Dugeasr \\ Department of Genetics and Plant Breeding, Allahabad School of Agriculture \\ Sam Higginbottom Institute of Agriculture, Technology and Sciences, Allahabad, (U.P.), India \\ *Corresponding author
}

\section{A B S T R A C T}

The laboratory Experiment entitled "Evaluation of seed quality parameters in coriander (Coriandrum sativum L.)" was carried out in the Seed Testing Laboratory, Department of

\section{Keywords}

Coriander, Seed vigour, Germination and Seed quality parameters

Article Info

Accepted: 04 June 2018 Available Online: 10 July 2018 Genetics and Plant Breeding, SHIATS, Allahabad. The objective of the present study was to assess physical, viability, seedling and vigour parameters of 10 coriander genotypes. Analysis of variances revealed the presence of considerable variation among the genotypes for all the characters viz., seed test weight $(\mathrm{g})$, seed density $\left(\mathrm{g} / \mathrm{cm}^{3}\right)$, germination $(\%)$, speed of germination (day-1), root length $(\mathrm{cm})$, shoot length $(\mathrm{cm})$, seedling length $(\mathrm{cm})$, vigour index length, seedling fresh weight(g), seedling dry weight $(\mathrm{g})$, seed vigour index mass and seed metabolic efficiency (SME). On the basis of mean performance for physical parameters best genotypes COR-86 has been identified as the best genotype for the seed quality parameters viz., seed test weight, germination (\%), speed of germination (days-1), root length $(\mathrm{cm})$, Shoot length $(\mathrm{cm})$, seedling length $(\mathrm{cm})$, seedling dry weight(gm.), seed vigour index length, seed vigour index mass and seed metabolic efficiency. Whereas genotype RKC-44 has found superior for germination (\%), speed of germination (days-1), root length $(\mathrm{cm})$, Shoot length $(\mathrm{cm})$, seedling length $(\mathrm{cm})$, seed vigour index length and seed vigour index mass.

\section{Introduction}

Coriander (Coriandrum sativum L.) is an important seed spices crop of family Apiaceae (Umbelliferae) and possess $2 \mathrm{n}=22$ chromosomes with cross-pollination as mode of reproduction. Western Europe and Asia are considered to be the centre of origin of this crop (Gal et al., 2010).Coriander is an annual herbaceous plant extensively grown in India. Its name has been derived from Greek world "Koris" means bed-bug, because of unpleasant, fetid bug like odour of the green unripened fruits (Meena et al., 2010). It is highly reputed ayurvedic medicinal plant commonly known as "Dhanya" in India. This plant is highly aromatic and has multiple uses in food and in other industries. Plants have played a critical role in maintaining human health and civilizing the quality of human life for thousands of years (Dhankar et al., 2011). The research study is commonly used to evaluate seed quality, is able to predict field emergence provided the conditions for 
emergence are favorable. Many authors found laboratory germination tests to correlate well with field emergence (Szczepanska et al., 1982).The assessment of seed physiological potential is usually performed through germination and vigor tests. The vigor tests are regarded as important for revealing relatively narrow variations in the different deterioration stages of the seeds of a seed lot (Baalbaki et al., 2009). Vigor is the potential for the establishment and good growth of the plantlets. Physiological quality of seeds as determined by an emergence test is not enough to predict storage potential of seeds (Stump et al., 1997). Hence, the present study of coriander genotypes was evaluated for qualitative parameters among ten genotypes of coriander seeds.

\section{Materials and Methods}

The present investigation was carried using ten coriander varieties. Experiment was conducted in the Seed Testing Laboratory, Department of Genetics and Plant Breeding, Faculty of Agriculture, Sam Higginbottom Institute of Agriculture, Technology and Sciences (Deemed- University), Allahabad.

\section{Observations were recorded}

Germination test was conducted in a complete randomized design with four replications. From each treatment, randomly 100 seeds are selected per replication were put for germination in the sterilized germination papers in Between paper method and incubated at normal light at room temperature and was recorded separately for each treatment and replication on final count $\left(21^{\text {st }}\right.$ day), (Fritze, 1965).

Germination percentage $=$

Total number of seed germinated

Total number of seed planted
Speed of germination was conducted in Top paper method and daily count on the number of germinated seeds was recorded separately for each treatment and replications till the final count (21st day) (Magurie, 1962).

Speed of germination $=n 1 / 1+n 2 / 2+n 3 / 3$ $+\ldots \ldots \ldots \ldots \ldots . . . n x / x=N$

Where $n 1 \ldots . . . \ldots . n x$ are the number of seeds germinated on day 1 to days $\mathrm{x}$ and $1 \ldots . . \mathrm{x}$ are number of days

Seed density was conducted by using kerosene test, seed test weight was observed by counting 1000 seeds of each variety separately and weighing there weights separately. The seedlings root lengths were measured after the final count in standard germination test. The seedlings root length $(\mathrm{cm})$ was measured from the point of attachment to the tip of the root (Fiala, 1987). The seedlings shoot lengths were measured after the final count in standard germination test. Ten normal seedlings were selected randomly from each replicate. The shoot length was measured from point of the attachment of the cotyledon to the tip of the seedling. Average shoot length $(\mathrm{cm})$ were computed by dividing the total shoot or root length by total number of normal seedlings measured (Fiala, 1987). Seedling Length $(\mathrm{cm})$ from the germination test, ten normal seedlings was selected randomly from each treatment on the day of final count. The seedling length was measured from tip of shoot to root tip and the mean length will be calculated and expressed as seedling length in centimeters. The total shoot length $(\mathrm{cm})$ or root length $(\mathrm{cm})$ by total number of normal seedlings measured. Seedling fresh weight was measured in grams after final count in the standard germination test. Ten seedlings selected randomly from each replicate were weighed to the nearest grams and the average fresh weight was calculated (ISTA 2001). The weight of seedling excluding the cotyledon 
was taken on 21 day after oven drying at $100^{\circ} \mathrm{C}$ for $24 \mathrm{hrs}$ in (g), (Wood Stock, 1976). Vigour index is computed by adopting the following formula as suggested by (Abdul Baki and Anderson, 1973) and expressed in number.

SVI=Germination $(\%) \times$ Seedling length $(\mathrm{cm}$.

It was calculated by multiplying the standard germination with mean seed used.

Seed vigour mass $=$ Germination $(\%)$ x Mean seedling dry weight $(\mathrm{g})$

Seed Metabolic Efficiency (SME)the amount of dry seed weight that is required for producing one gram of dry root and shoot is known as metabolic efficiency of the seed. Thus higher the value of seed metabolic efficiency, lower the efficiency of the seed as more seed reserve would be used for producing root and shoot. Amount of food material respired (RESP) will be calculated as

Seed Metabolic Efficiency $(\mathrm{SME})=\mathrm{SHW}+$ RTW/RESP

RESP $=$ SDW $-($ SHW + RTW + RSW $)$

Where,

SDW = Dry weight of seed before germination

SHW = Dry weight of shoot

RTW $=$ Dry weight of root

RSW $=$ Dry weight of seed after germination

These were worked out and the data was statistically analyzed using ANOVA.

\section{Results and Discussion}

The present investigation was carried using ten coriander varieties. Experiment was conducted in the Seed Testing Laboratory, Department of Genetics and Plant Breeding, Faculty of Agriculture, Sam Higginbottom
Institute of Agriculture, Technology and Sciences (Deemed- University), Allahabad.

\section{Observations were recorded}

Germination test was conducted in a complete randomized design with four replications. From each treatment, randomly 100 seeds are selected per replication were put for germination in the sterilized germination papers in Between paper method and incubated at normal light at room temperature and was recorded separately for each treatment and replication on final count $\left(21^{\text {st }}\right.$ day) (Fritze, 1965).

\section{Germination percentage $=$}

Total number of seed germinated x 100

Total number of seed planted

Speed of germination was conducted in Top paper method and daily count on the number of germinated seeds was recorded separately for each treatment and replications till the final count (21st day),(Magurie, 1962).

Speed of germination $=n 1 / 1+n 2 / 2+n 3 / 3$ $+\ldots \ldots \ldots \ldots \ldots . . . n x / x=N$

Where $n 1 . . . . . . . . n x$ are the number of seeds germinated on day 1 to days $\mathrm{x}$ and $1 \ldots . . \mathrm{x}$ are number of days

Seed density was conducted by using kerosene test, seed test weight was observed by counting 1000 seeds of each variety separately and weighing there weights separately. The seedlings root lengths were measured after the final count in standard germination test. The seedlings root length $(\mathrm{cm})$ was measured from the point of attachment to the tip of the root (Fiala, 1987). The seedlings shoot lengths were measured after the final count in standard germination test. Ten normal seedlings were selected randomly from each 
replicate. The shoot length was measured from point of the attachment of the cotyledon to the tip of the seedling. Average shoot length $(\mathrm{cm})$ were computed by dividing the total shoot or root length by total number of normal seedlings measured (Fiala, 1987). Seedling Length $(\mathrm{cm})$ from the germination test, ten normal seedlings was selected randomly from each treatment on the day of final count. The seedling length was measured from tip of shoot to root tip and the mean length will be calculated and expressed as seedling length in centimeters. The total shoot length $(\mathrm{cm})$ or root length $(\mathrm{cm})$ by total number of normal seedlings measured. Seedling fresh weight was measured in grams after final count in the standard germination test. Ten seedlings selected randomly from each replicate were weighed to the nearest grams and the average fresh weight was calculated (ISTA 2001).The weight of seedling excluding the cotyledon was taken on 21 day after oven drying at $100^{\circ} \mathrm{C}$ for $24 \mathrm{hrs}$ in $(\mathrm{g})$, (Wood Stock 1976). Vigour index is computed by adopting the following formula as suggested by (Abdul Baki and Anderson 1973) and expressed in number.

SVI=Germination $(\%)$ x Seedling length $(\mathrm{cm}$.

It was calculated by multiplying the standard germination with mean seed used.

Seed vigour mass $=$ Germination $(\%) \times$ Mean seedling dry weight $(\mathrm{g})$

Seed Metabolic Efficiency (SME)the amount of dry seed weight that is required for producing one gram of dry root and shoot is known as metabolic efficiency of the seed. Thus higher the value of seed metabolic efficiency, lower the efficiency of the seed as more seed reserve would be used for producing root and shoot. Amount of food material respired (RESP) will be calculated as Seed Metabolic Efficiency $($ SME $)=$ SHW + RTW/RESP (Table 1).

Table.1 Studies on seed and seedling quality parameters in Coriander

\begin{tabular}{|c|c|c|c|c|c|c|c|c|c|c|c|c|c|}
\hline \multicolumn{2}{|l|}{ 这 } & 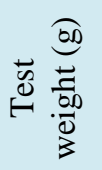 & 胥 & 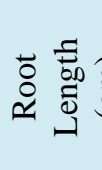 & 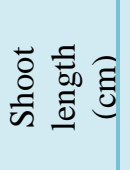 & 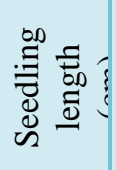 & 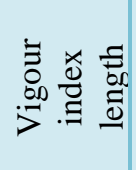 & 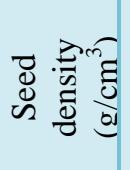 & 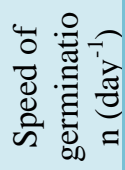 & 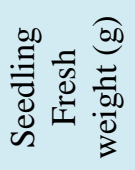 & 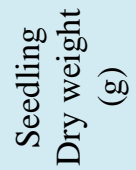 & 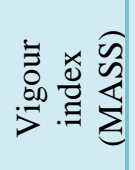 & 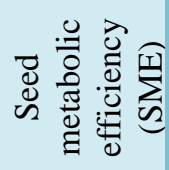 \\
\hline \multicolumn{2}{|c|}{ RKC-36 } & 14.175 & 70.75 & 6.45 & 7.72 & 14.47 & 1024 & 0.47 & 7.83 & 0.425 & 0.0475 & 3.35 & 3.14 \\
\hline \multicolumn{2}{|c|}{ RKC-44 } & 14.275 & 71.25 & 7.02 & 7.97 & 15.25 & 1086.25 & 0.47 & 8.13 & 0.475 & 0.0475 & 3.4 & 3.07 \\
\hline \multicolumn{2}{|c|}{ RKC-45 } & 10.175 & 68.75 & 6.42 & 7.7 & 14.12 & 970.75 & 0.51 & 6.79 & 0.375 & 0.04 & 2.75 & 4.67 \\
\hline \multicolumn{2}{|c|}{ RKC54 } & 10.625 & 67.25 & 6.1 & 7.4 & 13.5 & 907.5 & 0.53 & 6.63 & 0.575 & 0.037 & 2.52 & 3.58 \\
\hline \multicolumn{2}{|c|}{ RKC-55 } & 9.125 & 68.25 & 6.1 & 7.62 & 13.72 & 937 & 0.46 & 6.88 & 0.35 & 0.03 & 2.04 & 2.91 \\
\hline \multicolumn{2}{|c|}{ RKD-18 } & 9.725 & 67.75 & 6.55 & 7.37 & 13.92 & 936.62 & 0.48 & 7.46 & 0.525 & 0.03 & 2.03 & 2.60 \\
\hline \multicolumn{2}{|c|}{ UD-503 } & 8.175 & 66.75 & 5.72 & 6.87 & 12.6 & 840.87 & 0.42 & 6.50 & 0.4 & 0.03 & 2.00 & 3.75 \\
\hline \multicolumn{2}{|c|}{ UD-505 } & 14.475 & 67.25 & 6.22 & 7.67 & 13.9 & 935.12 & 0.47 & 6.68 & 0.45 & 0.047 & 3.2 & 2.96 \\
\hline \multicolumn{2}{|c|}{ UD-509 } & 10.175 & 69.25 & 6.52 & 7.62 & 14.15 & 980 & 0.51 & 7.19 & 0.5 & 0.04 & 2.77 & 4.71 \\
\hline \multicolumn{2}{|c|}{ COR-86 } & 14.675 & 72.25 & 7.17 & 8.22 & 15.67 & 1132.75 & 0.48 & 8.28 & 0.6 & 0.057 & 4.16 & 4.91 \\
\hline \multicolumn{2}{|c|}{ Grand mean } & 11.56 & 68.95 & 6.43 & 7.62 & 14.13 & 975.088 & 0.48 & 7.24 & 0.46 & 0.04 & 2.82 & 3.63 \\
\hline \multicolumn{2}{|c|}{ SE } & 0.07 & 0.15 & 0.14 & 0.17 & 0.25 & 25.74 & 0.01 & 0.33 & 0.03 & 0.0025 & 0.19 & 0.39 \\
\hline \multicolumn{2}{|c|}{$\mathrm{CD} 5 \%$} & 0.15 & 2.35 & 0.29 & 0.36 & 0.51 & 52.58 & 0.02 & 0.67 & 0.06 & 0.0051 & 0.40 & 0.79 \\
\hline \multicolumn{2}{|c|}{$\mathrm{CV}$} & 0.91 & 2.36 & 3.14 & 3.30 & 2.51 & 3.73 & 2.99 & 6.46 & 9.36 & 8.67 & 9.92 & 15.24 \\
\hline \multirow{2}{*}{ 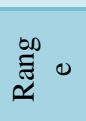 } & Max & 14.675 & 72.25 & 7.17 & 8.22 & 15.67 & 1132.75 & 0.53 & 8.28 & 0.6 & 0.057 & 4.16 & 4.91 \\
\hline & Min & 8.175 & 66.75 & 5.72 & 6.87 & 12.6 & 840.87 & 0.42 & 6.50 & 0.35 & 0.03 & 2.00 & 2.60 \\
\hline
\end{tabular}


$\mathrm{RESP}=\mathrm{SDW}-(\mathrm{SHW}+\mathrm{RTW}+\mathrm{RSW})$

Where,

SDW $=$ Dry weight of seed before germination

SHW $=$ Dry weight of shoot

RTW = Dry weight of root

$\mathrm{RSW}=$ Dry weight of seed after germination

These were worked out and the data was statistically analyzed using ANOVA.

\section{Seedling dry weight (gm)}

Seedling dry weight ranged from 0.057 to $0.03 \mathrm{~g}$ with the grand mean value of $0.04 \mathrm{~g}$. The maximum seedling dry weight was observed in the genotype COR-86 $(0.057 \mathrm{~g})$.Followed by the genotypes RKC-44 (0.0475), RKC-36 $(0.0475 \mathrm{~g})$, UD-505 (0.047g) and UD-509 $(0.04 \mathrm{~g})$. Whereas the minimum Seedling dry weight was observed in the genotype UD-503 $(0.03 \mathrm{~g})$ followed by RKD-18 (0.03g). Similar finding was observed by Krishnan et al.(1984).The increase in weight may be due to the rapid germination, which cause elongation of roots and resulted in increase in its weight.

\section{Vigour index mass}

Vigour index mass ranged from 4.16 to 2.0 with the grand mean value of 2.82 . The maximum viability was observed in the genotype COR-86 (4.16), followed by the genotypes RKC-44 (3.4), RKC-36 (3.35), UD-505 (3.2), UD509(2.77) and RKC-45 (2.75).

Whereas the minimum vigour index mass was observed in the genotype UD-503 (2.0) followed by RKD-18 (2.03). Beura et al., (2014) reported that high vigor seeds with high initial germination have greater vigor index mass.

\section{Seed metabolic efficiency}

Seed metabolic efficiency ranged from 4.91 to 2.60 with the grand mean value of 3.63. The maximum seed metabolic efficiency was observed in the genotype COR-86 (4.91), followed by the genotypes UD-509 (4.71), RKC-45 (4.67), UD-503 (3.75) and RKC-54 (3.58). Whereas the minimum seed metabolic efficiency was observed in the genotype RKD18 (2.60) followed by RKC-55 (2.91). Rao (1993) reported that the lower value of seed metabolic efficiency indicates the higher efficiency of seed because more dry matter will be produced from the reserves. It helps the seedlings to utilize lesser amount of reserve food for dry matter production.

It was concluded from the experiment that the genotype COR-86 has been identified as the best genotype for the seed quality parameters $v i z$, seed test weight $(\mathrm{g})$, germination $(\%)$, speed of germination (days-1), root length $(\mathrm{cm})$, Shoot length $(\mathrm{cm})$, seedling length $(\mathrm{cm})$, seedling dry weight $(\mathrm{g})$, seed vigour index length, seed vigour index mass and seed metabolic efficiency. followed by genotype RKC-44.

\section{References}

Abdul-Baki, A. A. and Anderson, J. D. (1973). Vigour and leaching of water soluble sugars from seeds of their species during storage under controlled conditions, Seed Research, 1: 99-114.

Baalbaki, R. Elias, S. Marcos-Filho, J. McDonald, M. B. (2009). Seed vigor testing handbook, Ithaca, Association of Official Seed Analysts, 341.

C. K. Pramila, K. P. R. Prasanna, P. Balakrishna, P. J. Devaraju and Siddaraju (2013). Assessment of seed quality in seed spices, Journal of Spices and Aromatic Crops, 22 (5): 233-237.

Dhankar, S. Kaur, R. Ruhil, S. Balhara, M. Dhankhar, S. Chhillar, A.K. (2011) A review on Justiciaadhatoda a potential source of natural medicine, African Journal of Plant Science, 620-627.

E. Capecka, E. Szalacha, B. Dąbrowska and K. Suchorska-Tropiło (2003) Influence of Pre sowing Conditioning and Fungicide Application on the Seed and Seedling Vigour and Yield of Coriander (Coriandrum sativum L.) Seeds Proc. IS 
on Sustainable, Use of Plant Biodiversity, 598.

Fiala, F. (1987) Handbook of Vigour Test Methods, International Seed Testing Association Publication.

Fritz, T. (1965), Germination and vigour test of cereals seed. Proceedings of the ISTA, 923-927.

Gal, G. Anwer, M. M. Meena, S. S. Mehta, R. S. and Maeria, S. P. (2010).Advances in Prodution technology of Coriander, National Research Centre on Seed Spices Ajmer Rajasthan, 1-5.

Hewston, L.J. (1964), Effect of seed size on crop performance on viability of seed, Chapman and Hall, London, 215-217.

ISTA (2001) Rules amendments 2001, Seed Science Technology, 29, supplement 2: 132.

J. K. BeuraA. Priyadarsini, R. K. Tarai, A. K. Kar and S. K. Swain (2016)Effect of Seed Treatment on Seed Quality Enhancement in Coriander, $A n$ international Quarterly Journal of Life Sciences, 11(1): 579-582.

Jacobson, R. and Globerson, D. (1980) Carrot seed quality in seed production, Hibblethwaite (Eds.) Butterworths Publication, 637-646.

Krishnan, B.M. and Kulasekaran, M. (1984), Studies on seed germination in wild ber (Zizphus roumdifolia), South Indian Horticulture, 32: 153-154.

Maguire, J. D. (1962) Speed of germination Aid in selection an evaluation for seedling emergence and vigour, Crop Science, 176-177.

Meena, M. L. Kumar, V. Kumar, S. Yadav, Y. C., and Kumar, A. (2010) Genetic variability, heritability, genetic advance, correlation coefficient and path analysis in coriander, Indian Journal of Horticulture, 242-246.

Nasar and Teamma (1994), Seed viability of wheat and lentil as affected by soil water suction (SWS), soil temperature and potassium chloride concentration, Department of Soil, Alexandria

Rao, S.S. and Shrivastava, M.N. (1993), Genetic variation and correlation studies in rainfed upland rice. Oryza.31: 228229.

S. Ambika V. Manonmani and G. Somasundaram (2014) Review on Effect of Seed Size on Seedling Vigour and Seed Yield, Research Journal of Seed Science, 7: 31-38.

Stumpf, C.L. Peske, S.T. Baudet, L. (1997) Storage potential of onion seeds hermetically packaged at low moisture content,Seed Science and Technology, 25: $25-33$.

Szafirowska, A. Grzesik, M. Habdas H. and Staniaszek, M. (2002) Improving germination and vigour of aged and stored onion seeds by matriconditioning, Acta Physiology Plantarum, 24: 167-171

Weiss E. A. (2002) Coriander, In Spice Crops, CABI Publishing, 243-261.

Wood, D.W., Longden, P.C. and Scott, R.K. (1977), Seed size variation, its extent, source and significance in field crops, Seed Science \& Technology, 5: 337-352.

Woodstock, L.W. (1976), Progress report on seed vigour tests, AOSA, North American Newsletter, 50 (2): 1-78.

\section{How to cite this article:}

Raj Kumar Suman, Kamal Kant, Surya Prakash Meena and Vijay Dugeasr. 2018. Evaluation of Seed Quality Parameters in Coriander (Coriandrum sativum L). Int.J.Curr.Microbiol.App.Sci. 7(07): 368-373. doi: https://doi.org/10.20546/ijcmas.2018.707.045 